\title{
Sentimento de Pertencimento e Desenvolvimento da Moralidade na Escola
}

\author{
Ana Archangelo* ๑, Tagiane Maria Rocha Luz (®, Claudia Regina Campanaro @), \\ \& Isabela Angeli Rodrigues (1) \\ Universidade Estadual de Campinas, Campinas, SP, Brasil
}

\begin{abstract}
RESUMO - O presente artigo discute a importância de a escola oferecer um "espaço para o brincar" para crianças que enfrentam conflitos morais sérios. Mediante a apresentação de vinhetas, analisa alguns diálogos travados durante o brincar em uma sala de aula, entre uma criança e uma bolsista participante do Programa Institucional de Bolsas de Iniciação à Docência - PIBID/Capes. À luz de conceitos da psicanálise, o estudo demonstra como o brincar promove um ambiente suficientemente bom que, com a ajuda de um adulto significativo, é vital para que aspectos morais sejam abordados sem moralismos ou racionalizações e para que o sentimento de pertencimento permita à criança usufruir mais profundamente do ambiente escolar.
\end{abstract}

PALAVRAS-CHAVE: moralidade, escola, Psicanálise, brincar, pertencimento

\section{The Sense of Belonging and the Development of Morality in Schools}

\begin{abstract}
This article discusses the importance of school offering a "space to play" for children who face serious moral conflicts. Through the presentation of vignettes, it analyzes some dialogues exchanges, during classroom playtime, between a child and a grant-holder participating in the PIBID/Capes Institutional Teacher Training Grant Program. In the light of psychoanalytical concepts, the study demonstrates how play promotes a good-enough environment that, with the help of a significant adult, is vital for moral aspects to be dealt without moralism or rationalizations, and for the feeling of belonging to allow a child to have a deeper enjoyment of the school environment.
\end{abstract}

KEYWORDS: morality, school, Psychoanalysis, play, sense of belonging

O desenvolvimento moral é tanto propósito da educação quanto condição para o desenrolar do trabalho educativo e do "ser no mundo", envolvendo inúmeros conflitos que merecem atenção e manejo por parte da escola. Considerando a importância da questão da moralidade na instituição escolar, em especial na atualidade, em que temas como conflitos morais, bullying e tolerância estão na ordem do dia, o objetivo deste artigo é analisar um caso vivido em uma escola pública da rede municipal do estado de São Paulo, em que aspectos morais da experiência de um aluno vêm à tona graças à aproximação de uma bolsista nos momentos destinados ao brincar. Entre 2011 e 2018, desenvolvemos um projeto que consistia na oferta semanal de um "espaço para o brincar" e de "contação de histórias" em sala de aula1. Uma de suas finalidades era propiciar vínculos afetivos suficientemente bons entre os adultos e as crianças e, consequentemente, ofertar meios de expansão intelectual, moral e emocional. Foram muitas

1 Trata-se de projeto vinculado ao Programa Institucional de Bolsas de Iniciação à Docência, financiado pela CAPES (PIBID/CAPES), no qual alunos de graduação de cursos de Licenciatura desenvolviam ações em escolas parceiras sob a supervisão de um professor-supervisor da mesma escola e um professor-orientador da universidade. O projeto articulava iniciação à docência com a investigação dos processos educativos, sociais e emocionais que se desenrolavam nas práticas propostas. Todos os participantes eram bolsistas CAPES, mas, no presente texto, identificaremos o aluno de graduação como "bolsista", no intuito de diferenciá-lo do professor de sala.

\footnotetext{
* E-mail: ana.archangelo@gmail.com

- Submetido: 08/08/2018; Aceito: 10/09/2020.
} 
as situações marcantes que se converteram em objeto de estudo cuidadoso. O presente trabalho privilegia a relação entre uma criança e uma bolsista do projeto, na qual se pode constatar a importância de a escola oferecer um "espaço para o brincar" para crianças que enfrentam conflitos morais sérios.

Algumas crianças não conseguem usufruir do ambiente escolar por não encontrarem a sustentação social, pedagógica, emocional e/ou intelectual necessária a esse processo que permite o "ser" e o "estar" na escola. Muitas delas vivem solitariamente seus conflitos morais ou então os veem expostos, indiscriminadamente, por profissionais que abusam da moralização e de racionalizações no trato de tais conflitos.

O estudo conclui que a experiência de estar com o outro, de sentir-se cuidado por alguém e de sentir-se parte de uma unidade para além de si mesmo é fundamental para o desenvolvimento e que a concretização do propósito educativo que se pretenda apartada da experiência de pertencimento pode conquistar pouco ou nada.

\section{MORALIDADE:ALGUNS APONTAMENTOS DA PSICANÁLISE}

A psicanálise sempre se preocupou com o desenvolvimento moral dos sujeitos. Mas tanto quanto a psicanálise, a concepção psicanalítica de desenvolvimento moral é múltipla. $\mathrm{O}$ presente artigo aborda alguns autores pós-freudianos que contribuem com a reflexão sobre esse tema.

Segundo Rustin (2001, p. 189), a abordagem kleiniana possibilita a compreensão de que os seres humanos são inatamente sociais, ou seja, somos dependentes do bemestar dos outros e preocupados com ele desde os primeiros meses de vida. ${ }^{2}$

Klein (1991) afirma que os relacionamentos humanos são em sua essência marcados pela ambivalência entre os sentimentos de amor e ódio e que a capacidade de odiar e de amar é inerente à natureza humana, portanto, constitutiva.

De acordo com Klein (1991), "as primeiras experiências do bebê com a alimentação e presença da mãe iniciam uma relação de objeto com ela" (p. 87). Ainda segundo a autora (Klein, 1991), os primeiros relacionamentos são estabelecidos com objetos parciais, sendo o objeto arcaico, fundamentalmente, o seio materno. Isso significa que as experiências de ansiedade vividas com o objeto-seio são separadas das experiências de conforto e satisfação vividas com esse mesmo objeto. Conforme Klein (1991), essa cisão é um dos principais mecanismos de defesa do ego primitivo. No início da vida pós-natal, portanto, um mesmo objetoseio é experimentado pelo bebê como dois: um que evoca ansiedade e ódio (aquele que não vem no momento da fome, que sufoca quando produz muito leite, que interrompe a mamada antes de saciar o bebê), outro que evoca satisfação e amor (aquele que nutre, que dá carinho, que socorre no momento de sofrimento).

Nesse período, além da cisão que separa a experiência de satisfação e de frustração com o objeto, dois outros mecanismos já estão presentes: o de projeção e o de introjeção. A projeção permite à psique dotar um objeto externo de conteúdos psíquicos presentes em si, mas não totalmente reconhecidos como próprios. A introjeção implica internalização de objetos externos, que são progressivamente

2 Tradução do autor. reconhecidos como objetos internos. Esses, por sua vez, podem se tornar tanto objetos de identificação quanto um conjunto de experiências acumuladas pelo ego, que dão forma a ele.

Klein (1991) expõe que, para o bebê, existem um seio bom, presente e gratificador, e um seio mau, ausente e hostil. O seio bom recebe projeções de sentimentos amáveis, e o seio mau, de sentimentos agressivos. Em contrapartida, as fantasias a respeito do seio bom ocasionam a introjeção de bons sentimentos, enquanto aquelas a respeito do seio mau provocam a introjeção de objetos hostis e persecutórios. Como projeção e introjeção são mecanismos de defesa utilizados para livrar a psique da ansiedade, tendencialmente, a primeira é utilizada para expulsão do objeto persecutório, que evoca ódio; a segunda, para incorporação de um objeto amoroso, capaz de aplacar o sofrimento psíquico relacionado ao temor da morte.

Para Klein (1991), os primeiros meses de vida são marcados pela idealização do seio bom e pela negação do seio mau. O bebê crê na existência de dois objetos externos com qualidades distintas e com os quais estabelece relacionamentos diferentes. $\mathrm{O}$ seio mau desperta ansiedades persecutórias; o seio bom, por sua vez, afasta as fantasias terroríficas despertadas pelo seio mau, restaurando a paz e a tranquilidade no mundo externo. Em decorrência da predominância de mecanismos de cisão, bem como da ansiedade persecutória nesses primeiros meses de vida, Klein (1991) nomeou esse modo de funcionamento mental de posição esquizoparanoide.

De acordo com Klein (1991), para o desenvolvimento psíquico, é fundamental a predominância de introjeção de objetos bons em relação a objetos maus. O objeto primordial que sedimentará as bases para o desenvolvimento emocional é o seio bom, ou seja, o seio presente: um 'ambiente suficientemente bom' é aquele no qual a ansiedade e os sentimentos destrutivos dela decorrentes são mantidos no limite do tolerável, e as propensões amorosas e de busca pela verdade do self são nutridas o suficiente para dar suporte ao desenvolvimento (Rustin, 2001, p. 196). ${ }^{3}$ 
O ambiente suficientemente bom possibilita a integração psíquica e contribui com o estabelecimento da posição depressiva, na qual, diferentemente da posição esquizoparanoide em que o objeto está cindido e, portanto, é parcial, o objeto passa a ser total, tornando possível a convivência da experiência com o seio bom, nutridor e com o seio mau, hostil, em um único objeto. A ansiedade persecutória, advinda do medo de destruição do self pelo objeto mau, diminui consideravelmente e a convivência com o objeto total faz predominar a preocupação com a integridade deste, a qual Klein (1991) denomina ansiedade depressiva. É da entrada na posição depressiva, portanto, que se desenrola o sentimento moral de preocupação com o outro já nos primeiros meses de vida. Porém, tais processos dependem não apenas das condições internas do bebê, mas também das condições externas nas quais alimento, cuidado, amor, desamparo e negligência podem ser ofertados em intensidade e frequência distintas. Em um ambiente facilitador, chamado por Winnicott (1983) de "suficientemente bom", ou seja, aquele que, em sua imperfeição, consegue atender e frustrar em uma medida justa, as incertezas e os desafios da realidade podem ser enfrentados, e a responsabilidade pelas consequências de ações e desejos pode ser assumida (Rustin, 2001, p. 196). ${ }^{4}$

Rustin (2001) chama ainda a atenção para o fato de que ambiente não se reduz ao outro da relação dual original ou ao ambiente doméstico, familiar. Portanto, a responsabilidade e o eventual fracasso ambiental dizem respeito ao conjunto das instituições e do que podemos chamar sociedade. Se as famílias, as escolas, os locais de trabalho, as vizinhanças e mesmo a sociedade política maior são os incubadores das capacidades morais, então as capacidades morais falharão quando tais instituições falharem (Rustin, 2001, p. 197). O modelo psicanalítico usado aqui entende esse processo como sendo de 'continência' (Rustin, 2001, p. 197). A menos que as ansiedades geradas por estresses normais da vida forem apropriadamente 'contidas' dentro de instituições que respeitam o valor dos indivíduos, elas gerarão formas destrutivas de defesa psíquica [grifos no original] (Rustin, 2001, p. 198) .

\section{PENSANDO O DESENVOLVIMENTO DA MORALIDADE NO INTERIOR DA ESCOLA}

Quando uma criança vai à escola, ela o faz a fim de tornar sua vida mais intensa, significativa e gratificante. Como pano de fundo, há também uma expectativa não apenas pessoal, mas também social, embora nem sempre consciente, de que ela aprofunde suas raízes na tradição em que vive.

Simone Weil (2001) descreve, no livro O Enraizamento, o que considera como necessidades da alma para que se criem raízes na cultura em que se vive. Segundo a autora (Weil, 2001),

o enraizamento é talvez a necessidade mais importante e mais desconhecida da alma humana. É uma das mais difíceis de definir. Um ser humano tem raiz por sua participação real, ativa e natural na existência de uma coletividade que conserva vivos certos tesouros do passado e certos pressentimentos do futuro. Participação natural, ou seja, ocasionada automaticamente pelo lugar, nascimento, profissão, meio. Cada ser humano precisa de múltiplas raízes. Precisa receber a quase totalidade de sua vida moral, intelectual, espiritual, por intermédio dos meios dos quais faz parte naturalmente. (p. 43)

A experiência propiciada no início da vida será crucial para o desenvolvimento psíquico e o funcionamento intelectual, condições para o enraizamento na cultura e o desenvolvimento do sentimento de pertencimento na escola. No entanto, por toda a vida, ambientes suficientemente bons podem proporcionar a progressão nos processos de maturação e/ou oferecer-se como curativos para experiências emocionais dolorosas. Isso ocorre na medida em que tais ambientes produzam uma atmosfera mais concatenada com o necessário para que o psiquismo possa se desenvolver. A escola pode ou não se constituir como esse ambiente. Por exemplo, dificuldades de relacionamento e de aprendizagem que se avolumam e, pouco a pouco, parecem a seus olhos não superáveis, constituem, para a criança, empecilhos no curso de seu enraizamento na cultura e, consequentemente, no sentimento de pertencimento em relação à escola.

Algumas necessidades como brincar, narrar, sonhar, aprender ou ensinar devem ter continuidade e evoluir no tempo e no espaço da realidade psíquica interna, em conjugação com a realidade externa. É no bojo de tais necessidades que a capacidade de se preocupar com o outro toma forma. As crianças que não puderam introjetar a contento o objeto bom por terem sido privadas ou deprivadas de um ambiente suficientemente bom, ou que são impedidas de ver atendidas tais necessidades, são mais vulneráveis à ansiedade persecutória, mais suscetíveis a operar psiquicamente na posição esquizoparanoide e, consequentemente, têm maior dificuldade de reconhecer o objeto total para o qual o ato de se preocupar se dirige.

Como já foi dito, na posição esquizoparanoide, predominam objetos internos maus, assim como um precário senso de realidade externa, que limitam os indivíduos ao estabelecimento de vínculos com objetos parciais - internos ou externos - tendencialmente depreciados ou ameaçadores. Resulta daí que tais vínculos são frágeis; os recursos psíquicos disponíveis para usufruir deles, sofríveis; e a capacidade para se preocupar com eles, mínima. Quando essas crianças

4 Tradução do autor.

5 Tradução do autor. 
vão para a escola, levam consigo as circunstâncias que tendem a dificultar o sentimento de pertencimento, que retroalimenta o processo de enraizamento à cultura. Mas, sobretudo, levam consigo a necessidade e a esperança de que a instituição ofereça o ambiente que reassegure os vínculos de confiança; reconheça suas necessidades, assim como o estado de sofrimento em que se encontram; legitime e valorize os movimentos de maior integração psíquica; acolha os de maior vulnerabilidade. Portanto, cabe à escola constituir-se como esse ambiente suficientemente bom, vital ao desenvolvimento das crianças.

Ao pensar em todas as etapas que um sujeito vive no transcorrer de sua existência, a infância é aquela que demarca o maior número de experiências novas - em seu estado mais puro. Quando criança, as experiências de medo, expectativas, ansiedades e frustrações dão tanto significado à vida emocional que, futuramente, irão ecoar em vivências semelhantes nas mais diversas combinações possíveis. Pensando nisso, podemos dizer que a escola é um dos ambientes mais significativos na vida de uma pessoa. É nela que grande parte da infância se desenrola. No entanto, para que a escola seja de fato significativa, é preciso que ela envolva pessoas, ideias e atividades que permitam à criança senti-la e experiencia-la como tal. Segundo Villela e Archangelo (2013), o ambiente escolar necessita desencadear três sentimentos subjacentes: acolhimento, reconhecimento e pertencimento.

$\mathrm{O}$ acolhimento pressupõe receptividade. Isso significa que a escola deve ser capaz de receber a criança em seus mais variados estados de espírito. Por ser um espaço que abriga pessoas dotadas de história e não apenas sujeitos dotados de cognição, a escola precisa abraçar desde situações de aflição até as de conquista; precisa ter seus "braços abertos" para permitir à criança visualizar e perceber esse espaço como acolhedor, capaz de lidar com as angústias típicas do existir humano. Ainda no que tange aos aspectos de uma escola significativa, o reconhecimento aparece como outro elemento essencial nesse grande tripé que forma o sustentáculo dos espaços-tempo da escola.

Ao mesmo tempo em que oferece espaço para as singularidades, a escola reconhece nelas a universalidade das experiências humanas e, portanto, a possibilidade de aceitá-las, compreendê-las e compartilhá-las. Reconhecer é, portanto, uma maneira profunda de dizer ao aluno que somos todos participantes de uma mesma história (Villela \& Archangelo, 2013).

Sendo acolhida e reconhecida, a criança pode também reverberar o sentimento de pertencimento. Expressar-se e envolver-se nos contextos e nas oportunidades oferecidos pela escola passam a ser experiências cotidianas e espontâneas. Suas ações não estarão referidas a notas e elogios (ainda que os envolvam), pois ultrapassarão essa esfera da externalidade. As ações serão significadas pelo que podem cultivar ao seu redor, naquele e em todos os outros espaços que envolvem outros contextos e pessoas.

Especialmente quando constantemente acompanhado dos sentimentos de acolhimento e de reconhecimento do aluno pela escola, o sentimento de pertencimento aprofunda a percepção do aluno, em grande medida inconsciente, de que ele pertence àquele espaço, de que a escola é seu local natural, de que grande parte de suas oportunidades de crescimento e felicidade está ali. (Villela \& Archangelo, 2013, p. 44)

Algumas crianças com as quais tivemos contato claramente não experimentaram os sentimentos descritos acima. A escola, por sua vez, muitas vezes reconhece que não sabe como acolhê-las. Com o oferecimento do momento para o brincar, propiciado pelo projeto que mencionamos na introdução deste texto, construímos possibilidades de intervenção empática às crianças e, ao serem também objeto de investigação, elas nos revelaram aspectos importantes do desenvolvimento, incluindo o da moralidade, suas vicissitudes e sua relação com as dificuldades no sentimento de pertencimento.

\section{A IMPORTÂNCIA DE BRINCAR NA ESCOLA}

Com a finalidade de oferecer um espaço suficientemente bom, propício à integração e à manifestação do "ser" na escola, foi criado um "momento para o brincar" em 10 salas de $1^{\circ}$ a $5^{\circ}$ anos do Ensino Fundamental de uma escola pública municipal, em uma cidade média do estado de São Paulo. A cada ano, entre 2011 e 2018, aproximadamente 290 crianças eram atendidas semanalmente com a oferta do "momento para o brincar" - uma hora em cada classe, em período regular de aula -, acompanhado por um bolsista, aluno de graduação, e pelo professor da turma. Além da atividade de acompanhamento do "momento para o brincar", os bolsistas também investigavam os processos psíquicos ali em jogo e participavam de reuniões semanais de supervisão e aprofundamento de estudo. Em linhas gerais, o trabalho envolvia relatórios de observação e de intervenção; discussão nos grupos de supervisão; análise e interpretação dos aspectos descritos, realizadas a partir dos relatórios e dos registros dos bolsistas sobre sua experiência emocional com as crianças. As discussões sobre as leituras ocorriam previamente e, em geral, abordavam autores das áreas de educação e psicanálise; as supervisões dos casos descritos nos relatórios dos bolsistas também eram feitas à luz desses referenciais, pelas coordenadoras do grupo. A socialização dos relatórios sobre os acontecimentos das salas dos colegas promovia uma experiência compartilhada, (re) pensada e dialogada.

Durante o brincar, eram utilizados dois baús com diversos brinquedos em cada sala de aula. Os baús foram 
inspirados em literatura especializada sobre jogo simbólico e sobre análise de crianças (Klein, 1991). Os critérios de seleção dos brinquedos são importantes, pois divergem daqueles que regem a tendência da escola a fazer uso de brinquedos pedagógicos em situações lúdicas. Faziam parte dos kits carrinhos, panelinhas, bonecas, bonecos e bebês de diferentes etnias, animais, heróis, caminhões, apetrechos de salão de beleza, massinha de modelar, lousa mágica, entre outros. Alguns poucos jogos de tabuleiro e memória compunham os kits para atender algumas crianças que, por algum tempo, não conseguiam se integrar com as demais ou com o adulto nos jogos simbólicos e precisavam de jogos mais relacionais como etapa preparatória para o engajamento com os outros brinquedos.

Benjamin (1984) afirma que os brinquedos são, a princípio, objetos incógnitos, antes de entrarem no campo de visão e de manipulação de uma criança. Após isso, tornam-se matéria-prima para sua criatividade e para o seu vir a ser. Winnicott (1990), observando a importância do brincar na vida da criança, explica que ele é a expressão original do viver criativo, fruto da criatividade. Tanto para a fantasia quanto para o alcance da objetividade, o brincar envolve atividade simbólica.

Tal como as personalidades dos adultos se desenvolvem por suas experiências de vida, as das crianças evoluem por intermédio de suas próprias brincadeiras e das invenções feitas por outras crianças e por adultos. Ao enriquecerem-se, as crianças ampliam gradualmente sua capacidade de exagerar a riqueza do mundo externamente real. A brincadeira é a prova evidente e constante da capacidade criadora, que quer dizer vivência. (Winnicott, 1990, p. 163)

Algumas das crianças que encontramos na escola pareciam ter se desviado a caminho da conquista da capacidade de brincar. Em função disso, perderam muitas oportunidades de criar, de amadurecer, de se sentir cuidadas e de experimentar o cuidado para com o outro - elemento crucial para o desenvolvimento da moralidade, conforme nos apontam os autores citados.

No "momento do brincar", era preciso ser uma mente disponível, o que demandava atenção por parte dos bolsistas no desenrolar das brincadeiras, sobretudo na falta delas. Diante de um não brincar, por exemplo, era preciso que o bolsista identificasse a natureza da dificuldade da criança e manejasse as condições necessárias para que ela voltasse a brincar ou desenvolvesse a capacidade para brincar espontaneamente. $\mathrm{O}$ grau de presença e intervenção do bolsista variava, a depender da necessidade do aluno nos mais diversos contextos em que as resistências se apresentavam. Tal intervenção permitia à criança habitar os territórios da fantasia e da criatividade, de modo que encontrasse no bolsista e no "momento do brincar" um espaço seguro, livre e confiável para a manifestação e a expressão de seu mundo interno.

Em consonância com os achados de Winnicott (1975), vínhamos constatando que os alunos com maiores dificuldades no campo da aprendizagem e do relacionamento eram, em geral, os mesmos que não conseguiam brincar. Os demais usualmente brincavam tranquilos, sozinhos ou acompanhados por outras crianças. O espaço para o brincar possibilitava ao professor e ao bolsista que dedicassem maior atenção a crianças com dificuldades de aprendizagem e de relacionamento, com a intenção de estabelecer um vínculo suficientemente bom e de estimular o brincar espontâneo e o desenvolvimento de seu potencial criativo.

O brincar na escola permitia que essas oportunidades fossem oferecidas às crianças, assim como fornecia elementos fundamentais para uma revisão radical das prioridades da instituição escolar, no que tange aos seus objetivos.

Aqui trazemos um estudo de caso no qual as experiências vividas por uma criança são apresentadas como um recorte singular que, por sua vez, é também expressão de dinâmicas gerais. Isto porque observamos várias outras situações similares em que os conflitos se apresentavam e a presença do adulto no brincar proporcionava sua abordagem de maneira menos racionalizada e mais vivencial na relação com a criança.

Dada tal relação entre o particular e os aspectos gerais da experiência vivida por inúmeras crianças, o caso a seguir oferece elementos para pensarmos a escola como um ambiente "suficientemente bom", onde os conflitos inerentes ao desenvolvimento moral encontram sustentação. Em outras palavras, um ambiente de experiência do sentimento de pertencimento e da perspectiva de enraizamento.

\section{UMA DISCUSSÃO SOBRE A MORALIDADE NO CONTEXTO DO BRINCAR}

\section{Lyan e o seu Videogame Wii}

O garoto Lyan ${ }^{6}$ era aluno de terceiro ano do Ensino Fundamental. Seu rendimento escolar era precário e ele frequentemente presenteava colegas com montes de balas

6 Os nomes utilizados no texto são fictícios. e chicletes. O relacionamento com eles era perpassado por frequentes rompantes de agressividade e por esses lampejos de "generosidade". Certa vez, enquanto brincava, aproximou-se da bolsista graduanda. A vinheta seguinte é uma adaptação do relatório dela.

Lyan brincava de família junto com outras crianças, utilizando os bonecos e, sem nenhum questionamento da minha parte, ele 
começa a me contar [coisas sobre sua família]. A forma como ele me contou foi bastante confusa, e demorei pra entender a lógica de sua família. [Disse que o pai] se ausenta para fazer os "corres". Questionei Lyan sobre o que significava isso - os "corres". Ele ficou bastante constrangido, não sabia se me contava, se mudava de assunto. Então, percebendo sua reação, levei-o para um cantinho reservado da sala de aula. Falei que o que ele me dissesse seria o nosso segredo. Nisso, ele me conta que o pai rouba "nas casas dos ricos". Tentei não demonstrar, mas não sabia como reagir ou o que falar diante da situação. Resolvi então perguntar a opinião do Lyan sobre a postura do pai. Ele respondeu não gostar da atitude do pai, mas que gostava dos presentes que ele dava, e revelou que seu mais novo presente tinha sido um Nintendo Wii [grifo nosso].

Os doces que distribuía entre os colegas eram, sabidamente, fruto dos "corres" do adulto que, de tempos em tempos, presenteava Lyan com uma soma incompatível com a condição social da família. Embora extraísse satisfação de certo prestígio que a doação de doces lhe conferia, assim como dos presentes que ganhava do pai, o garoto demonstrou reconhecer os sinais de que tal satisfação dizia respeito a algo moralmente questionável. O conflito entre preocupar-se com sua própria satisfação (ao presentear ou ao ser presenteado) ou com o dano causado aos outros nos "corres" do pai não foi criado pela experiência de brincar, mas não se pode ignorar que foi a brincadeira de família o gatilho para que ele ganhasse forma, palavra e escuta em sala de aula.

$\mathrm{O}$ aprofundamento de suas experiências, bem como das possibilidades de expressão, de envolvimento com os outros e de compreensão, contudo, traz consigo um duplo efeito: tanto pode permitir que situações conflitivas encontrem solução como o contrário, que elas se asseverem. Aquelas situações sobre as quais pairavam sinais algumas vezes imperceptíveis, outras vezes reconhecíveis em seu comportamento agressivo, mas em geral não apreensíveis ou não comunicáveis do conflito existente, vêm à tona $\mathrm{e}$ exigem uma resposta do outro, mesmo que tal resposta seja apenas sua presença incondicional, empática e silenciosa.

No caso de Lyan, certa ideia difusa de que "os ricos merecem ser roubados" e "ele e seus amigos merecem os presentes", típica da posição esquizoparanoide, convive com o conflito moral, que ultrapassa essa cisão entre objetos maus (os ricos) e bons (ele e os amigos), alcançando outro patamar de funcionamento mental, no qual aspectos bons e maus estão integrados em ambos os objetos. O mesmo conflito alcança sua relação com o pai, a quem ama (objeto bom), mas que é capaz de fazer algo (roubar) que Lyan considera errado (objeto mau). Para desenvolver-se psiquicamente e se manter nesse novo patamar esboçado na conversa com a bolsista, mais próximo da posição depressiva, forças internas potentes que estão em conflito precisam se enfrentar. Pessoas a quem ama cometem delitos. No psiquismo de Lyan, a satisfação dos membros de sua família está diretamente relacionada a um dano causado a outros (as pessoas roubadas). $\mathrm{O}$ prestígio que ele obtinha junto aos colegas, com as balas e os chicletes, tanto quanto o prazer de usufruir do videogame que muitos de seus colegas não tinham, custava a ele a culpa por se beneficiar de um ato que considerava errado e que já reconhecia como socialmente reprovável.

São enfrentamentos a que crianças na idade de Lyan não deveriam estar tão duramente submetidas. Mas a realidade cruel assim se impôs e o importante a partir desse dado é pensarmos quão danoso seria ao menino não encontrar ajuda para tolerar o sofrimento presente em sua experiência. À primeira vista, a manutenção do primeiro patamar de funcionamento mental parece uma solução viável. Ou seja, parece psiquicamente confortável que o menino opere uma divisão dos objetos, relacionando-se com objetos parciais. Dessa forma, as pessoas próximas, que lhe trazem sustento e satisfação, permaneceriam como objetos bons, e os outros, sem rosto e sem utilidade para ele, seriam depositários de tudo de ruim, odioso e persecutório que circula em seu dia a dia.

Mas mecanismos de cisão e projeção, conforme nos aponta Klein (1991), não são benéficos quando predominantes e utilizados maciçamente. É com a integração do objeto e com a predominância de processos de introjeção dos aspectos amorosos deste que se constitui certa capacidade de reconhecer os danos que provocamos nos objetos que amamos. Esse reconhecimento, por sua vez, é a base da posição depressiva, da capacidade de preocuparse com o outro e do desenvolvimento moral.

Outro prejuízo decorrente da permanência na posição esquizoparanoide é a constituição de um mundo interno precário. A precariedade viria, de um lado, do empobrecimento acarretado pelo excesso de expulsão de aspectos próprios indesejados, pela fantasia de que essa expulsão liberaria permanentemente o psiquismo do sofrimento. De outro lado, tal precariedade derivaria da fragilidade dos processos introjetivos constitutivos dos objetos bons internos. Objetos internos se prestam, como dito anteriormente, a processos identificatórios, os quais, por sua vez, colaboram com o desenvolvimento do ego. Mecanismos predominantemente projetivos almejam esvaziar o psiquismo dos objetos maus (Klein \& Riviere, 1975), mas acabam por levar consigo as partes boas do ego.

Outro retrato dos conflitos vividos por Lyan aparece na situação vivenciada por ele em companhia de outra graduanda-bolsista, durante o período do recreio, e relatada a seguir:

Durante o recreio, Lyan ameaça chamar um colega mais velho para bater em Pietro, o qual teria chamado uma outra colega de "orelha de Shrek"... Depois de certo tempo, Pietro pede desculpas, mas Lyan não parece se acalmar o suficiente. Então, eu continuo "gente... o Pietro tá errado, mas ele tá pedindo desculpas. Ele vai parar". Lyan, andando, ia dizendo "sai fora... Ninguém mandou ele xingar a menina". Eu disse "calma, Lyan...". Caminhamos um pouco, paramos ao final das salas, próximos ao portão dos fundos da escola. Perguntei "Por que você ia chamar um menino pra bater no Pietro?". Bravo, Lyan argumentou "ah, mano... sai fora! Por que que ele foi xingar 
a menina? A menina é pequena... Ninguém mandou!". Então, eu disse "tá... então, tá. Eu entendo que você quer defender a menina, e que você achou errado o que o Pietro fez. E eu também acho errado. Tá errado, mesmo. Mas, de que adianta? Você ficou bravo porque o Pietro xingou a menina, e agora você quer ir lá chamar outro menino pra bater no Pietro? Ele xingou, e agora você quer bater... Você percebe que está querendo resolver uma coisa errada, com outra coisa errada?". Lyan parecia ter "caído em si". Então, continuei "Lyan... quando é assim, se você quer ajudar, você conversa... Primeiro fala com o Pietro, ou quem for. Se não resolver, você me procura, procura alguém que esteja aqui no pátio, procura a professora... e aí a gente conversa com o Pietro... E a gente resolve. Não é batendo que a gente vai ajudar". Lyan comentou "então, se ele não parar eu vou falar com a Rita". Eu disse "isso! Agora o Pietro pediu desculpas... a gente já conversou. Mas, se mesmo assim ele xingar a menina de novo, você vai e fala com a Rita". O menino assentiu. Comentei "então, tá combinado?". Lyan acenou positivamente com a cabeça. Agradeci "obrigada por me ouvir e por entender".

Em relação ao episódio todo, é possível notar a raiva pela qual Lyan se deixou tomar e a presença de um senso de justiça no menino. Porém, seu senso de justiça está construído ainda sobre as bases da lei de talião, típica da posição esquizoparanoide. Ele crê que a maneira de corrigir um erro é com uma agressão física. Se pensarmos nas revelações de Lyan sobre os "corres" do pai e no conflito que esses representam, perceberemos que a posição esquizoparanoide oferece recursos psíquicos limitados.

Na luta entre amor e ódio, no âmago de Lyan, tende a prevalecer a lógica moral do ódio. O "bateu, levou", bastante disseminado em nosso convívio social, é um mecanismo mobilizado no mundo interno da criança em decorrência da ansiedade persecutória. Mas a experiência vivida por Lyan nas situações da escola oferece espaço para continência de tal ansiedade. Como se pode perceber no relato, a atitude do adulto está longe de lançar mão exclusivamente de um código moral a ser intelectualmente apropriado pelo menino. Acolher o menino nos braços, aguentando suas investidas para se desvencilhar, caminhar com ele por um tempo, chegar a um local reservado, anunciar que quer falar apenas com ele, como que compartilhando algo muito profundo e íntimo, e, fundamentalmente, reconhecer a preocupação legítima dele com a injustiça com a menina, oferecendo a mente adulta para suportar problemas futuros para, finalmente, demonstrar preocupação profunda com o sofrimento de Lyan em sua experiência contraditória de querer justiça cometendo injustiça são elementos centrais para um manejo bem-sucedido.

Quando a fala do adulto apenas remete a criança ao "certo e errado" ou, o que é pior, apenas ao que ela fez "de errado", a ansiedade persecutória e o ódio tendem a recrudescer. Nesses casos, infelizmente, a escola não percebe mudança na atitude do aluno e tende a intensificar a abordagem normativa e punitiva. Lyan talvez não tenha entendido em profundidade a questão lançada pela bolsista a ele, porém, compreendeu a comunicação inconsciente que se estabeleceu. Por isso, respondeu: "Tá bom! Mas, se ele mexer de novo com ela, vou falar com a Rita!", reconhecendo sua dificuldade em manejar a contradição interna por conta própria, mas buscando o suporte adulto que encontrou nessa experiência - ou, em outras palavras, buscando identificar-se com o objeto bom.

Quando impedido de se identificar com objetos internos bons e levado a se identificar com objetos internos predominantemente maus, Lyan tem objetos depreciados e ameaçadores como elementos de identificação. Em outras palavras, tende a se considerar, consciente e inconscientemente, como fraco, inábil, pouco inteligente, ou como mau, destinado a fazer maldades e a ameaçar os outros para obter o que quer. Diante do predomínio desse modo de funcionamento mental, seu esforço pessoal e o envolvimento com suas atividades de criança não são suficientes, pois o que ele é capaz de extrair do que recebe nessas relações está estragado, é pouco, não presta, ou é contra ele. Trata-se, portanto, de um dano profundo à capacidade do menino de aprimorar-se, de sentir-se como objeto de valor.

Seu senso de justiça só pode operar no patamar da retaliação, na absoluta correspondência entre o "crime e a pena". Isso ocorre porque o funcionamento mental que ignora o objeto total - no qual aspectos bons e maus estão integrados - não pode reconhecer, naquele que "faz o mal", alguma característica que o torne capaz de aprender o certo, de reconhecer o próprio erro, ou de reconhecer o dano provocado, de modo a repará-lo. Mas isso pode ser superado ao introjetar também objetos bons e se identificar com eles (a menina agredida, o menino capaz de protegê-la e o adulto capaz de sustentar o manejo de seus conflitos). Sentindo-se objeto de valor, tem forças para reconhecer em si também aspectos mais valorosos.

É o espaço para o brincar que recupera, para Lyan, o espaço de apresentação das camadas mais profundas desses conflitos. É no espaço para o brincar que a escola se torna o ambiente capaz de acolhê-los.

No brincar, foi possível perceber que Lyan se considerava como alguém que dependia dos "corres" para encontrar alguma satisfação. Mas foi ali também que se tornou possível para ele encontrar satisfação na experiência de estar com os amigos, com os brinquedos e com a bolsista - uma pessoa de confiança, que se preocupava verdadeiramente com ele e com as dificuldades que ele atravessava.

A capacidade de brincar, duramente conquistada por Lyan, e que proporcionava a ele espaço mental de interação entre mundo interno e externo, mediante o uso do brinquedo e o uso do adulto significativo, fez com que o menino estabelecesse uma relação de progressiva confiança com o ambiente e com a bolsista de sua sala. Costumava falar sobre acontecimentos cotidianos durante o brincar. Em todas as ocasiões, estavam presentes elementos que refletiam a situação conflitiva em que se encontrava, bem como aspectos de culpabilidade.

Pouco a pouco, porém, a intensidade do conflito se acentuou. Com isso, o lugar da expressão oral ou da expressão simbólica proporcionada pelo brincar foi sendo 
ocupado, na escola, por atos relacionados diretamente aos conflitos vividos fora da escola, seguidos de profundo sentimento de culpa. Um deles está descrito abaixo:

Brincava com as meninas de cabeleireiro quando Pedro me fala sobre Lyan. Disse que Lyan havia colocado um brinquedo que ele trouxe de casa na mochila. Como de costume, chamo Lyan para conversar. Nesse instante, o garoto fica agressivo com Pedro. Questiono Lyan sobre o que havia acontecido, deixo claro o que o amigo disse, mas digo que gostaria de ouvir dele o que aconteceu. Peço então que me conte. Imediatamente, o comportamento do garoto muda, demonstrando ansiedade diante da situação. Reforço, então, que estávamos apenas conversando e que estava ali para ajudá-lo a resolver aquele problema sem julgar qualquer que tivesse sido sua atitude. Após um longo silêncio, o aluno conta que guardou o brinquedo do amigo em sua mochila porque o brinquedo era muito legal, mas que devolveria. Pergunto então o que ele achava do que havia feito. Em lágrimas, ele não respondeu.

O choro do garoto ao devolver o brinquedo parece indicar a luta travada em seu interior. A satisfação imediata em um ambiente que ama (levar para casa o brinquedo e, por extensão, o ambiente do brincar) oblitera outra satisfação, não imediata: a de se sentir capaz de se preocupar com os outros e com os danos que causa ao colega e ao próprio espaço do brincar. De outro lado, a chance de devolver o brinquedo e identificar-se com um ambiente que, na figura dos colegas, do conhecimento, da professora e da bolsista, não lhe oferece satisfações imediatas; que exige dele esforço e empenho, mas que tem sido capaz de acolher seu sofrimento e sua culpa, considerando-os aspectos legítimos e relevantes de sua experiência de crescimento. O conflito não é de fácil manejo, assim como não o é quando o pai, objeto de amor, levava-o a participar dos furtos e do repasse de drogas. Tal manejo se impõe como desafio moral cotidiano e exige acolhimento constante por parte do adulto, incluindose aí uma atitude interpretativa que, embora não resulte em interpretação direta à criança, serve de guia ao processo de acolhimento a ser vivido entre adulto e criança.

Parafraseando Rogers (2007) sobre uma de suas alunas, alguns carregam uma história que não podem contar em forma de narrativa. Como o autor descreve: "she carried a story she could not relate as a narrative. Instead, she cut her arms." [Ela carregava uma história que não podia contar em foram de narrativa. Em vez disso, ela cortava seus braços $]^{7}$ (Rogers, 2007, p. 38). Dessa forma, é o esforço interpretativo que promove no adulto algum grau de integração dos fragmentos dispersos da experiência da criança, de modo a orientar sua ação, sem ultrapassar seu papel de educador e sem negligenciar aquilo que se desenrola a sua frente.

Ainda assim, sabemos que nem sempre o tempo da escola coincide com o tempo do processo vivido pela criança na companhia do educador. O período de férias, por exemplo,

7 Tradução do autor. pode mobilizar sentimentos contraditórios e reestabelecer um afastamento entre a criança e o adulto. É o que nos mostra o trecho a seguir, extraído de relato da bolsista.

As atividades na escola seriam retomadas naquela manhã. As crianças se alegram ao me ver depois de um mês de férias. Entre histórias, perguntas, demonstrações de carinho das crianças, avisto Lyan no fundo da sala, quieto, como se aquele momento não fosse significativo para ele. Assim que as crianças se acalmam e voltam para seus lugares, vou até o aluno, ajo como se não houvesse percebido sua reação, digo que senti sua falta e pergunto como foram as férias. Enfático, o aluno diz não querer falar comigo, e se retira da sala. Durante a manhã, outras tentativas de aproximação foram feitas, porém com a mesma reação do aluno.

Apesar do afastamento e de uma aparente piora, o que podemos notar é que Lyan estava em franca luta interna, o que, nesse caso, é bastante positivo. O processo vivido por Lyan evidencia quão dolorosa e repleta de idas e vindas é a transição da posição esquizoparanoide para um novo patamar de funcionamento mental, particularmente na situação em que o garoto se encontrava. Ele parece ter sido mobilizado profundamente, principalmente durante as férias. $\mathrm{O}$ afastamento de Lyan em relação à bolsista parece ter um duplo sentido: tanto porque ela evoca nele o sofrimento que o conflito interno e a culpa desencadeiam, quanto porque, ao se ausentar nas férias, ela o teria traído, abandonando-o à própria sorte, com todo o seu sofrimento, sozinho.

Após o episódio das férias, por um bom tempo foram recorrentes as saídas do aluno da sala, fazendo com que se ausentasse do brincar por diversas vezes. Durante esse período, era incapaz de se envolver nas brincadeiras; ia até os diferentes grupos que brincavam, mas sem efetivamente participar de nenhum deles e nem criar alguma brincadeira. Foram ficando cada vez mais frequentes, em forma de desenho ou escrita, registros dos furtos e repasses de drogas. Isso também parece evidenciar o quanto a espontaneidade no brincar - em proporções muito maiores do que a vivida em atividades regulares de aula - põe em xeque os valores morais de Lyan. Tendo sustentado essa volta às aulas mais hostil e desafiadora, a bolsista, a professora de sala e a escola começaram a ver despertar um Lyan mais engajado nas atividades escolares, principalmente nas de contação de histórias.

Passado algum tempo da volta às aulas, coincidentemente, a escola passou a oferecer aulas de tae-kwon-do no contraturno. A professora de sala relatou que, algumas semanas mais tarde, Lyan procurou-a e disse: "Professora, a escola resolveu dar essas aulas pra gente não ficar na rua, não é?". Também tivemos notícia de que Lyan fazia empréstimos na biblioteca de todos os livros infantis lidos pela bolsista em sua sala. Em paralelo, Lyan conversou com a professora de outra turma, pedindo a ela permissão para contar histórias para os colegas. Ele ensaiava o trânsito entre a posição de ouvinte e a de contador de histórias; demonstrava que a 
contação de histórias, amparada pelo brincar e pela atitude dos adultos, tornou possível o que Rogers (2007, p. 41) menciona: "showing how they could use others' words to create their own messages" [mostrar como eles podem usar a palavra de outros para criar suas próprias mensagens] $]^{8}$.

Como afirma Rustin (2001), o melhor cuidado que a sociedade pode prover é a profilaxia, através de um ambiente suficientemente bom desde os primeiros meses de vida. No entanto, nem sempre isso acontece. Principalmente em sociedades muito desiguais, as provisões ambientais estão longe de fornecer o necessário para uma grande parte da população. Nesses casos, ambientes que deveriam ser suficientemente bons são substituídos por outros excessivamente perturbadores. Pessoas que deveriam oferecer cuidado e proteção lançam suas crianças em experiências em que perigo, medo e ameaça são frequentes. Os conflitos intrínsecos ao psiquismo em desenvolvimento são assim intensificados, dificultando em demasia os processos de integração do objeto, de elaboração da culpa, de constituição de processos de reparação.

A tarefa das instituições sociais, contudo, é a de incansavelmente buscar formas de prover as condições de superação de tais dificuldades. Na escola, por exemplo, é possível que os ambientes excessivamente perturbadores sejam contrastados com um ambiente suficientemente bom. O "espaço para o brincar" buscava oferecer esse ambiente, assim como a "contação". A presença de um adulto confiável e preocupado com o bem-estar da criança e com o sofrimento que a ela tem sido imposto é um desses elementos de contraste. As possibilidades de simbolização dos conflitos oferecidas pelo brincar também contrastam com a necessidade de atuação do conflito, representada, por exemplo, na presença do furto em sala de aula. O bom relacionamento com os colegas e as atitudes deles são novas chances de introjeção de bons objetos.

Para um menino da idade de Lyan, podemos dizer que os conflitos morais a ele impostos eram demasiados. Todavia, embora os elementos específicos da história de Lyan não sejam comuns a todos os alunos, eles ilustram, em tintas mais fortes, conflitos morais que habitam as experiências infantis. Como procuramos demonstrar, a presença de um espaço para brincar e de um adulto confiável permitiu a expressão da dor desse conflito e o desenvolvimento de uma preocupação moral mais integrada e integradora.
O menino passou a experimentar, ainda que inconstantemente, outro patamar de relacionamento com os colegas e com o conhecimento, muito mais baseado no seu próprio eu, naquilo que seu empenho e engajamento podiam ofertar e receber de gratificação. Também podemos dizer que, ao reconhecer a iniciativa da escola de ofertar as aulas de tae-kwon-do e ao repassar aos colegas a satisfação da contação de histórias, Lyan pôde usufruir do cuidado e manifestar gratidão.

Winnicott (2005) enfatiza que o sentimento de gratidão é algo decorrente da melhora da criança, mas não se deve esperar por ele. Klein (1991) afirma que a gratidão só é possível quando o sujeito alcança a posição depressiva. Portanto, mesmo que as oscilações nas atitudes de Lyan não nos permitissem afirmar que esse fosse seu modo de funcionamento mental predominante, já podíamos ver lampejos dele.

De acordo com Winnicott (2005), a intervenção com fins empáticos à saúde emocional da criança não prevê a imposição de códigos morais. As crianças, em alguns momentos, serão insuportáveis, e o papel do elo que acolhe a dependência é o de lidar com a situação sem retaliar. $\mathrm{O}$ autor expõe ainda que há a necessidade de não se ligarem as dificuldades ou sintomatologias das crianças ao pecado. Diz Winnicott (2005): "nada se ganha em usar uma categoria moralista em vez de um código diagnóstico, sendo este último baseado verdadeiramente na etiologia, isto é, na pessoa e no caráter de cada criança" (p. 256).

Como nos ensina Rustin (2001), a premissa guia é que, onde qualidades apropriadas de cuidado são oferecidas (cuidado que responde às necessidades físicas e emocionais), a grande maioria dos indivíduos desenvolverá capacidades normais de amor e preocupação moral, misturado, sim, com impulsos mais destrutivos, mas que usualmente são contidos. Enquanto a rivalidade, por exemplo, com disputas na família e seus equivalentes simbólicos em grupos de brincadeira, sala de aula ou amigos é um estado mental normal; o compromisso parental, ou quase parental, com cada criança e a justiça em relação a elas normalmente atenuam a sua severidade e capacitam o desenvolvimento da partilha e da reciprocidade por meio da identificação. A fonte primária das disposições e capacidades morais reside no oferecimento de um "ambiente suficientemente bom" [grifo no original] (Rustin, 2001, p. 196) .

\section{CONSIDERAÇÕES}

Acreditamos que, se adotado permanentemente, o brincar em sala de aula pode contribuir com a superação de inúmeras dificuldades que têm se arrastado nos anos iniciais,

8 Tradução do autor.

9 Tradução do autor. chegando às séries mais avançadas. Preocupar-se com a criança que não brinca e não narra, e intervir para que ela passe a fazê-lo, embora pareça simples e pouco importante, na verdade é uma atitude que fornece as bases sobre as quais os desenvolvimentos emocional e intelectual se dão. Todo o trabalho de ensino fica facilitado (e, em alguns casos, torna-se possível) quando tais bases são fortalecidas. 
Disponibilizar um espaço no qual nós educadores testemunhamos a atuação das crianças no brincar, em atividades escolares ou, ainda, em momentos mais descontraídos como o recreio, nos permitiu oferecer terra fértil para desenvolver o sentimento de pertencimento e, em alguns casos, consequentemente, superar a dificuldade para se sentir pertencente a um grupo ou a uma instituição capaz de cuidar e de se preocupar com todos e com cada um.

A despeito de todas as armadilhas impostas pelos conflitos de Lyan ao ambiente escolar, este foi capaz de sobreviver, de acolher e reconhecer as batalhas enfrentadas pelo menino, o que não é fácil. Ainda parafraseando Rogers (2007), mesmo procurando ouvir e estar com a criança, muitas vezes queremos fugir. Ainda assim, precisamos criar o espaço para que a história da criança emerja. Ou seja, cabe à escola se manter como um ambiente suficientemente bom. Ao fazê-lo, acaba por testemunhar o reconhecimento do aluno em relação à escola. Para Lyan, por exemplo, é essa escola acolhedora que permite que o sentimento de pertença se enraíze, pois pode se converter em objeto de identificação, fazendo frente a objetos depreciados e ameaçadores. Uma escola capaz de cuidar, proteger e oferecer meios de satisfação que não dependam de mal impingido ao outro. No interior dessa escola, as bases de desenvolvimento moral que transcendam a lei de talião estão dadas. Cada "maldade" de Lyan acolhida pela escola como uma parte conflitante dele e não como o "atestado de sua malevolência", foi the dando a possibilidade de integração de suas partes boas e más, de sua destrutividade e sua capacidade de confiar, de ser justo, de amar aquele ambiente e os professores que se mostravam preocupados com os perigos que o mundo impõe a ele.

$\mathrm{O}$ acolhimento e o reconhecimento das dificuldades emocionais das crianças promovem o sentimento de pertencimento, e os professores das salas atendidas compartilham dessa percepção. Uma instituição escolar certamente deve ter os processos de ensino e aprendizagem como fim. Contudo, ao considerarmos a importância do aspecto emocional nesses processos, visamos à formação integral da criança na escola e para além dela.

\section{REFERÊNCIAS}

Benjamin, W. (1984). A criança, o brinquedo e a educação. Summus.

Klein, M. (1991). Inveja e gratidão e outros trabalhos (1946 1963). Imago.

Klein, M., \& Riviere, J. (1975). Amor, ódio e reparação. Imago. Rogers, A. G. (2007). The unsayable. Ballantine Books.

Rustin, M. (2001). Innate morality: A psychoanalytic approach to moral education. In M. Rustin, Reason and unreason: Psychoanalysis, science and politics (pp. 185-200). Continuum.
Villela, F. C. B., \& Archangelo, A. (2013). Fundamentos da escola significativa. Loyola.

Weil, S. (2001). O enraizamento. Edusc.

Winnicott, D. W. (1975). O brincar e a realidade. Imago.

Winnicott, D. W. (1983). O ambiente e os processos de maturação: Estudos sobre a teoria do desenvolvimento emocional. Artmed.

Winnicott, D. W. (1990). Natureza humana. Imago.

Winnicott, D. W. (2005). Privação e delinqüência (4 ${ }^{\mathrm{a}}$ ed.). Martins Fontes. 